\title{
DISTRIBUIÇÃO DAS OPORTUNIDADES EDUCACIONAIS NA REGIÃO METROPOLITANA DE CAMPINAS À LUZ DO ÍNDICE DE OPORTUNIDADE DA EDUCAÇÃO BRASILEIRA (IOEB)
}

\section{EDUCATIONAL OPPORTUNITIES IN THE CAMPINAS METROPOLITAN REGION IN LIGHT OF THE BRAZILIAN EDUCATION OPPORTUNITY INDEX (IOEB)}

\author{
Leandro Barbosa Oliveira
}

\section{RESUMO}

Este artigo aborda a distribuição das oportunidades educacionais na Região Metropolitana de Campinas (RMC) sob a ótica do Índice de Oportunidades da Educação Brasileira (IOEB), indicador criado no ano de 2015. O estudo objetivou-se compreender, através da análise das variáveis relacionadas a fatores de insumos e resultados que compõem o IOEB, as principais tendências em termos de oportunidades educacionais existentes nos municípios que constituem a RMC. Os resultados obtidos permitiram apontar os seguintes aspectos: a) as oportunidades não estão diretamente relacionadas aos fatores socioeconômicos; b) os municípios de Hortolândia (SP) e Paulínia (SP) estão em um mesmo patamar de oportunidades educacionais, apesar do primeiro possuir características socioeconômicas distintas do segundo; c) os resultados estão intrínsecos às práticas de gestão que prezam pelo bom desempenho no processo socioeducativo.

PALAVRAS-CHAVE: IOEB. Políticas públicas em educação. Oportunidades Educacionais.

\section{ABSTRACT}

This article deals with the distribution of educational opportunities in the Metropolitan Region of Campinas (RMC) under the Brazilian Opportunities Index of Education (IOEB), an indicator created in the year 2015. The study aimed at knowing, through the analysis of related variables the input and output factors that make up the IOEB, the main trends in terms of educational opportunities existing in the municipalities that make up the RMC. The obtained results allowed pointing the following aspects: a) the opportunities are not directly related to socioeconomic factors; b) the municipalities of Hortolândia (SP) and Paulínia (SP) are at the same level of educational opportunities, although the first municipality has socio-economic characteristics diametrically different from the second; $c)$ the results are intrinsic to an management practices that value good performance in the socio-educational process.

KEYWORDS: IOEB. Public policies of education. Educational Opportunities.

1 Mestrando em Educação pela Pontifícia Universidade Católica de Campinas, membro do grupo de pesquisa "Gestão e Políticas Públicas em Educação, desenvolvendo pesquisas na área de avaliação da educação básica, especificamente avaliação de sistemas educacionais e desempenho escolar. Possui também pós-graduação em Gerenciamento Ambiental pela Universidade de São Paulo (USP), licenciatura e bacharel em Geografia pela Universidade Estadual Paulista (UNESP). Profissionalmente atuando como professor de Geografia na rede municipal de Sumaré e também na rede estadual de educação. 


\section{INTRODUÇÃO}

Diante do panorama das demandas de mercado a educação é colocada em uma posição estratégica como fator de desenvolvimento socioeconômico de um país. Nesta perspectiva, pesquisas que englobam as boas práticas ${ }^{2}$ relacionadas ao bom desempenho educacional fornecem importantes elementos como fonte para a formulação de políticas públicas. É nesta vertente que este estudo se reconhece como instrumento para revelar cenários e realidades que, devidamente analisadas, podem contribuir para o aprimoramento das políticas públicas educacionais.

O país, estados e municípios têm buscado monitorar a performance do alunado através de avaliações externas, visando direcionar suas políticas educacionais e sintetizar resultados em indicadores de desempenho educacional. Conforme explicitado por Soares e Xavier (2013, p. 905), o uso de resultados de rendimento e aprendizado no acompanhamento de sistemas de educação, se justifica pelo fato que "apenas dessa forma, o Estado toma conhecimento se o direito à educação está sendo atendido, pois, na ausência de um sistema como esse, o direito público subjetivo estabelecido no texto constitucional não pode ser monitorado e, eventualmente, exigido".

A partir da década de 1990, o uso de avaliações externas para mensurar a qualidade educacional oferecida pelas escolas brasileiras tornou-se paradigma no cenário educacional. Exemplos desses indicadores são, em âmbito federal, o Índice de Desenvolvimento da Educação Básica (Ideb), que é elaborado segundo as variáveis do Sistema da Educação Básica (SAEB) e do Censo Escolar e, em escala estadual, o Índice de Desenvolvimento da Educação do Estado de São Paulo (Idesp), que trata do desempenho medido em testes padronizados e por questionários de contexto social, aplicados aos sujeitos envolvidos no processo de avaliação, e são tomados como instrumentos precisos para a geração de informações com credibilidade (MADAUS; RUSSEL; HIGGINS, 2009).

2 Segundo Farah (2008, p. 113), o conceito de melhores práticas ou best practices implica uma visão de inovação como uma solução completa, fechada e integral, a qual, implicitamente, prescreve um modo específico e único de responder a um desafio ou problema.
Nesse contexto de busca pela responsabilização dos índices educacionais, surgiu no ano de 2015 um novo indicador denominado Índice de Oportunidades da Educação Brasileira (IOEB), com o intuito de "agregar informações sobre as oportunidades educacionais oferecidas para todas as crianças e jovens em um município ou estado, identificando o quanto cada cidade ou estado contribui para o sucesso educacional dos indivíduos que lá vivem" (IOEB, 2015, p.1). Neste sentido, de acordo com esse índice, as melhores oportunidades são aquelas na qual os alunos têm acesso e permanência na escola, acompanhada com um bom desempenho acadêmico.

Em vista disso, o objetivo deste artigo é compreender, através da análise das variáveis relacionadas a fatores de insumos e resultados que compõem o IOEB, as principais tendências em termos de oportunidades educacionais existentes nos municípios que constituem a Região Metropolitana de Campinas, localizada no interior do Estado de São Paulo (SP). Diferente de outros indicadores, o IOEB relaciona indicadores de desempenho com as taxas de insumos e processos educacionais (escolaridade dos professores, experiência dos diretores, número de horas-aula/dia, taxa de atendimento da educação infantil). Esse modo de avaliação é importante, principalmente, porque permite que gestões de sucesso sejam compartilhadas visando um sistema de educação eficaz para garantir a eficiência educacional e qualidade administrativa.

\section{O ÍNDICE DE OPORTUNIDADES DA EDUCAÇÃO BRASILEIRA (IOEB)}

O Índice de Oportunidades da Educação tem seu caráter regional (avalia municípios e estados), representando a qualidade de oportunidades educacionais presentes em determinado espaço geográfico. Para aferir de maneira ampla as variáveis presentes em contexto escolar, que até então não eram mensuradas nas avaliações em larga escala, os criadores do IOEB, Reynaldo Fernandes e Fabiana Felício, utilizaram como critérios essenciais:

(1) Que as fontes sejam oficiais; (2) Que tenha uma periodicidade de divulgação habitual de até 2 anos para permitir o cálculo bienal do IOEB; 
(3) Que haja resultados divulgados ao nível do município já que o índice pretende identificar a qualidade nos municípios, além de estados e Distrito Federal; (4) Que as variáveis sejam possíveis indicadores de (i) insumos educacionais, ou seja, fatores determinantes de um bom resultado educacional ou de (ii) resultado da educação básica, seja ele de atendimento, de aprendizado ou de aproveitamento escolar. (CENTRO DE LIDERANÇA PÚBLICA (CLP), 2015, p. 8).

Logo, a partir da definição dos critérios utilizados para a composição do IOEB, são consideradas as seguintes variáveis para compor o modelo:

a) Indicadores de resultados educacionais: Ideb anos iniciais do ensino fundamental; Ideb anos finais do ensino fundamental; taxa líquida de matrícula do ensino médio.

b) Indicadores de insumos e processos educacionais: escolaridade dos professores; número médio de horas-aula/dia; experiência dos diretores; taxa de atendimento na educação infantil.

c) Controle de background familiar: escolaridade média dos pais.

Uma vez com as variáveis tabuladas e quantificadas, o indicador de oportunidades educacionais é mensurado com base no resultado da equação abaixo:

IOEB $=\alpha I_{p}+(1-\alpha) I_{R}$

$I_{P}=a_{1}$ escolaridade_profs $+a_{2}$ experiência_dir_3oumais $+a_{3}$ experiência_dir_6oumais + $a_{4}$ horas_aula $+a_{5}$ AtendEI

$I_{R}=\lambda_{1} I D E B_{-} A j_{A I}+\lambda_{2} I I D E B_{-} A j_{A F}+\lambda_{3} M a t_{-} L i ́ q 15 a 17_{-} A j$

Conforme descrito pelo CLP (2015, p.15) as varáveis referentes aos insumos atuam com um peso de $33,5 \%$, enquanto as de resultado $66,5 \%$, sendo essa última, portanto, mais influente no resultado final do IOEB.

\section{A REGIÃO METROPOLITANA DE CAMPINAS (RCM)}

Segundo o Instituto Brasileiro de Geografia e Estatística (IBGE), uma região metropolitana é definida como um aglomerado urbano composto por agrupamentos de municípios limítrofes, autônomos administrativamente, que se caracterizam pelo objetivo de integrar a organização, o planejamento e a execução de funções públicas de interesse comum. O processo de expansão, integração política e econômica des- te aglomerado urbano conecta cidades-satélites com municípios adjacentes, constituindo uma área urbana contínua com grandes dimensões, onde são comuns o deslocamento diário de pessoas entre municípios, para fins, por exemplo, de trabalho e estudo (IBGE, 2017; (BUGNI; JACOB, 2017).

A Região Metropolitana de Campinas foi criada em 24 de maio de 2000, como unidade regional do Estado de São Paulo, pela Assembleia Legislativa através da Lei Complementar $n^{\circ} 870$, sancionada pelo então governador Mário Covas em 19 de junho de 2000. A RMC abrange 19 municípios, sendo eles: Americana, Artur Nogueira, Campinas, Cosmópolis, Engenheiro Coelho, Holambra, Hortolândia, Indaiatuba, Itatiba, Jaguariúna, Monte Mor, Nova Odessa, Paulínia, Pedreira, Santa Bárbara D’Oeste, Santo Antônio de Posse, Sumaré, Valinhos e Vinhedo. Com população estimada em 2,2 milhões de habitantes, apresenta características socioeconômicas múltiplas e multifacetadas, atributos comuns em regiões metropolitanas.

O modo como se deu a institucionalização dos municípios que compõem a RMC gerou a formação de diferentes núcleos urbanos, ocasionando a descentralização em relação ao município de Campinas. Como resultado desse processo de urbanização, a região nucleada por Campinas pode ser classificada como uma metrópole emergente, não apenas no que diz respeito à sua força econômica, mas também pela alta concentração demográfica e integração econômica que têm sido acentuadas nas últimas três décadas (CUNHA, 2006).

A expansão urbana na RMC é acompanhada de um processo de intensa periferização, cujos bairros são formados sem infraestrutura básica, muitas vezes, configurando-se como moradias irregulares (como nos municípios de Hortolândia e Artur Nogueira). Por outro lado, houve o surgimento de ilhas de prosperidade ${ }^{3}$, nas quais determinada população, com maior poder aquisitivo, passou a morar em condomínios localizados em cidades próximas a Campinas (Valinhos e Vinhedo, por exemplo). No caso da RMC, o planejamento integrado dos municípios que a compõem torna-se fator fundamental para sua delimitação a partir da inte-

3 A autossegregação em condomínios fechados, por exemplo, é uma forma de morar que se utiliza da violência e da insegurança como meio de convencimento, oferecendo assim proteção, tranquilidade e outras amenidades, como o contato com a natureza, além do convívio com os iguais. 
gração socioespacial, da fluidez entre os municípios, e de análises e processos dos fenômenos sociais que se manifestam em seu interior.

Em função disso, quando o assunto são os sistemas de ensino na RMC, é necessário haver clareza quanto às peculiaridades relacionadas a cada município, pois estes, de maneira geral, possuem as próprias redes de ensino. Como efeito, cada município pode construir a própria política educacional nos limites da prerrogativa legal.

\section{DIFERENÇAS REGIONAIS, OPORTUNIDADES EDUCACIONAIS E VULNERABILIDADE SOCIAL}

O fim da década de 1980 é marcada pela proliferação de estudos no campo da sociologia urbana que buscam, além da abordagem dos fatores da origem socioeconômica da família, os fatores que a organização social do território exerce sobre as desigualdades educacionais (MADAUS; AIRASIAN; KELLAGHAN, 1980; WILSON, 1987; JENCKS; MAYER, 1990). Sendo assim, a confluência dessas abordagens contribuiu para a ampliação das investigações dos mecanismos geradores das desigualdades de oportunidades educacionais.

Ribeiro e Koslinski (2009), ao analisar com cautela os processos de segregação socioespacial, construíram referências quanto aos "efeitos dos contextos sociais de vizinhança sobre os processos de assimilação dos indivíduos na ordem social competitiva" (p. 356). Tais estudos, estabelecem relações de causalidade entre o indivíduo (motivações, escolhas, comportamento e situação social) e os contextos sociais em que residem.

Nesta perspectiva, os efeitos de influência da vizinhança podem interferir de forma positiva, na hipótese de uma vizinhança afluente, ou negativamente, no caso de vizinhanças carentes nos níveis de oportunidades educacionais. Conforme Koslinski, Lasmar e Alves (2012, p. 11) a "segregação urbana permite predizer a existência de piores oportunidades ao nível local, o que afeta a maneira pela qual os indivíduos percebem essas oportunidades". Os autores, ao abordarem a evolução dos estudos da sociologia da educação, mencionaram, além do efeito família e escola, a importância da vizinhança e do bairro enquanto "[...] instância capaz de gerar desigualdades educacionais" (p. 10).

A obra de W. J. Wilson, The truly disadvantaged, publicada em 1987, oxigenou as discussões inerentes ao efeito vizinhança e suas influências sobre oportunidades educacionais para indivíduos que vivem em áreas segregadas. Para Wilson, a concentração da pobreza resulta no isolamento dos pobres em relação às classes mais elevadas e ao distanciamento de seus correspondentes modelos, recursos e redes de trabalho.

Flores (2006), assinala que o isolamento social reforça, de forma legítima e perpétua, a distância entre os ethos (comportamentos, idiossincrasias) particulares de cada camada social, que apontam de maneiras distintas as práticas, crenças e hábitos de cada uma. Seria, então, através desse processo de segregação socioespacial, o desempenho escolar e, consequentemente, a avaliação da própria escola, impactadas negativamente.

Nesse sentido, a necessidade do estudo das relações sociais existentes nas mais variadas facetas de ordenamento espacial é terreno fértil para o desenvolvimento da geografia das oportunidades, que, segundo Galster e Killen (1995), se torna relevante ao considerar a dimensão educacional dentro da complexidade dos centros urbanos, em termos de acesso aos bens culturais e distribuição de recursos. Assim, para os autores, torna-se claro, que para tratar da igualdade de oportunidades de forma rigorosa é necessário considerar o elemento geográfico.

A relevância da reflexão sobre o papel do espaço nas relações sociais é determinante para estudar regiões metropolitanas, tais como a Região Metropolitana de Campinas (RMC), devido aos imensos contrastes existentes nas populações que formam tais áreas. O padrão urbano ocorrido na região apresenta uma dualidade entre as cidades que abrigam a população, predominantemente, de classes alta e média e, as cidades marcadas pelo predomínio de classes mais baixas. Nas primeiras, encontram-se boas moradias e investimentos em infraestrutura e equipamentos $^{4}$, por outro lado, nas cidades mais pobres, além de moradias mais precárias, a infraestrutura e

4 Segundo a NBR 9284, equipamento urbano são todos os bens públicos e privados, de utilidade pública, destinados à prestação de serviços necessários ao funcionamento da cidade, implantados mediante autorização do poder público, em espaços públicos e privados. Suas categorias são: circulação e transporte, cultura e religião, esporte e lazer, infraestrutura (comunicação, energia e saneamento), segurança pública, proteção, educação e saúde. 
os equipamentos disponíveis não atendem de maneira satisfatória à população.

Para Galster e Killen (1995), a ideia de igualdade de oportunidades está centralizada na dimensão do processo, o que se concretiza na estrutura de oportunidades (sistemas sociais, mercados e instituições). Ainda conforme os autores, "dois jovens com características pessoais idênticas não são susceptíveis de tomar as mesmas decisões de vida se residirem em diferentes partes de uma mesma região metropolitana" (p. 24), considerando que as regiões metropolitanas são geograficamente diferenciadas e as redes sociais locais podem induzir os jovens a tomarem decisões que os encaminhem para um estado de privação. Os autores consideram a rede social ${ }^{5}$ local um componente fundamental da estrutura de oportunidades, que desempenha papel relevante no fornecimento e avaliação das orientações, moldando as percepções.

Partindo do enfoque das desigualdades vivenciadas segundo o contexto geográfico, Galster e Killen (1995), desenvolveram o conceito de geografia de oportunidades relacionando o processo de tomada de decisão com o contexto geográfico dos indivíduos, os quais são dotados de aspectos objetivos e subjetivos que variam regionalmente. De acordo com esse aspecto intrínseco aos indivíduos, tem-se duas ramificações da geografia, sendo elas, a geografia objetiva de oportunidades e a geografia subjetiva de oportunidades.

A geografia subjetiva de oportunidades trata dos valores, aspirações, preferências e percepções subjetivas sobre como estão estruturadas as oportunidades educacionais em determinado espaço geográfico e, como essas oportunidades atendem às necessidades da comunidade envolvida em torno dela. De outra forma, a geografia objetiva de oportunidades refere-se aos dispositivos de rede urbana que variam espacialmente, sendo mais complexa em regiões com nível socioeconômico mais elevado, e apresentando precariedade em regiões de vulnerabilidade social ${ }^{6}$.

5 As redes sociais locais são compostas por familiares, vizinhos, amigos, parentes e instituições formais locais como clubes, associações e organizações religiosas.

6 Conforme Kaztman e Filgueira (2006), tal dinâmica de reprodução das desigualdades socioespaciais pode ser expressa considerando o conceito de vulnerabilidade social, que enfoca a capacidade de um dado grupo social tem de aproveitar as oportunidades disponíveis em diferentes áreas socioeconômicas, para promover o bem-estar e a qualidade de utilização de bens e recursos.
O modelo teórico em questão conflui para o fenômeno da causalidade das formas em que o espaço é configurado, que emergem dos primeiros estudos sobre segregação desenvolvidos nas décadas de 1920 e 1930, nos Estados Unidos, inerentes à formação dos guetos residenciais formados a partir da urbanização consequente da revolução industrial (BICHIR, 2006).

No espaço latino-americano, os estudos envolvendo a temática de segregação urbana foram desenvolvidos décadas depois. Kaztman e Retamoso (2005) citam dois padrões de segregação que ocorreram na América Latina: 1) típico das décadas de 1960 e 1970, acontece no contexto da industrialização (substituição de importações), motivado por um grande fluxo migratório de trabalhadores pouco qualificados para viver nas grandes cidades que surgiam, passando a se aglomerar nas zonas periféricas desses grandes centros urbanos; 2) movimentação dos trabalhadores pouco qualificados para os setores informais da economia. A partir da conjunção desses dois fatores, esses trabalhadores vivenciavam um verdadeiro isolamento social, além da própria segregação, a questão da precariedade, instabilidade do trabalho e segmentação dos serviços, ou seja, a existência de necessidades relativas aos serviços oferecidos à população.

O processo de industrialização trouxe consigo os processos de expansão urbana e de formação das metrópoles. Em países periféricos, como, por exemplo, o Brasil, o processo capitalista de formação dos grandes centros industriais ocorreu tardiamente, somente a partir dos anos 1960, momento também em que se deu a expansão das indústrias para o interior (SANTOS, 1998). Dessa forma, os estudos brasileiros voltados ao contexto das questões urbanas e das formas de estruturação do espaço geográfico surgiram a partir dos anos 1970.

Na literatura nacional acerca das consequências negativas da segregação residencial, são mencionados dois fatores que impactam negativamente a qualidade de ensino das populações que vivem em áreas socioeconomicamente desfavorecidas: o isolamento social e a ausência de acesso às políticas sociais (AZEVEDO, 2009). No contexto que engloba a qualidade educacional, este último ponto faz referência à universalização da educação básica, que consiste na ampliação da qualidade de ensino, muitas vezes precária em áreas 
segregadas. Nesse caso, o desempenho escolar dos alunos pode estar diretamente relacionado à localização da residência, bem como dos estabelecimentos de ensino (TORRES; GOMES, 2002) ${ }^{7}$.

Entre as principais causas do baixo desempenho dos estudantes brasileiros, Birdsall, Bruns e Sabot (1996), apontam questões socioeconômicas, de políticas públicas e demográficas. Nessa gama de variáveis apresentadas, as mais importantes são: 1) alta desigualdade de renda e oportunidades, o que resulta em pobreza; 2) má administração e distribuição de gastos públicos com educação; 3 ) alta fecundidade no passado, que resultou em um rápido crescimento no número de crianças em idade escolar. Este cenário impôs ao país a necessidade de priorizar a quantidade (expansão das matrículas) e menosprezar a qualidade de ensino.

De acordo com Ribeiro (2014), a educação é o fator mais importante para proporcionar mobilidade social e, o nível educacional permite ao indivíduo ocupar certas posições privilegiadas, além de the dar melhores condições de vida. De forma complementar podese citar Cunha et al. (2009), que destaca a educação como instrumento capaz de garantir a homogeneização social, no entanto, se a qualidade do serviço variar em termos qualitativos de acordo com a região geográfica, sendo inferior em áreas de vulnerabilidade social com a geração de desigualdade de desempenho entre os estudantes, a educação não poderá minimizar a transmissão intergeracional da pobreza.

Com base nisso, pode-se considerar a educação como um instrumento capaz de viabilizar a homogeneização social, porém está condicionada à qualidade dos serviços educacionais distribuídos de maneira desigual, principalmente nas áreas mais carentes. Logo, as pessoas inseridas nesse contexto geográfico têm a qualidade do ensino oferecido comprometida, gerando consequentemente a perpetuação de sua condição socioeconômica.

A reflexão sobre tal abordagem permite trazer ao debate as concepções de Jonh Rawls (2008), que compreende o papel desempenhado pelas instituições sociais no tocante à justiça social. Grosso modo, Rawls demonstra exigir que os recursos necessitam estar comprometidos, em um primeiro momento, com as pessoas mais vulneráveis de tal modo a elevar-lhes a expectativa, quanto à realização de seus anseios e considerem-se inseridos dentro de uma sociedade.

Assim sendo, a educação deve procurar diminuir as desigualdades e que essas não devem ser vistas sob a ótica da economia ou do bem-estar social, mas principalmente como meio para propiciar as pessoas o desfrute da cultura de uma sociedade, podendo, consequentemente, participar das atividades sociais. Como efeito, a educação reforçaria o senso de valor do indivíduo, garantindo as condições políticas, jurídicas e sociais "ao exercício da autonomia dos cidadãos considerados pessoas morais livres e iguais" (RAWLS, 2008, p.4) ${ }^{7}$.

Nessa perspectiva, pode-se inferir que faz parte dos deveres sociais (entende-se o Estado e as instituições responsáveis, isto é, aquelas que possuem competência para tal) oferecer igualdade de oportunidades de educação para todos os cidadãos, especialmente, para aqueles com talentos e dotes naturais semelhantes, que em virtude de sua condição de vulnerabilidade social ocupam posições desfavoráveis para a competição com aqueles, que mesmo possuindo aptidões semelhantes, encontram-se em situação social favorecida.

Outrossim, através do oferecimento de oportunidades equitativas de formação educacional, tem-se na educação o elemento que permite o acesso aos bens primários, entre os quais a autoestima como elemento de suma importância. Desse modo, o valor educacional não é medido pela eficiência, mas, essencialmente por permitir que o indivíduo se aproprie da cultura de sua sociedade e de toda produção cultural humana.

\section{METODOLOGIA}

O presente estudo segue os princípios da pesquisa bibliográfica, pois realiza contato direto com o conteúdo, possibilitando um exame do tema sob nova abordagem (MARCONI; LAKATOS, 2003); exploratória, que segundo Gil (2002), tem como objetivo proporcionar uma visão geral, do tipo aproximativo, acerca de

7 Cada pessoa possui uma inviolabilidade fundada na justiça que nem o bem-estar de toda sociedade pode desconsiderar. Por isso, a justiça nega que a perda da liberdade de alguns se justifique por um bem maior desfrutado por outros. Não permite que os sacrifícios impostos a poucos sejam contrabalançados pelo maior número de vantagens de que desfrutam muitos. Por conseguinte, na sociedade justa as liberdades da cidadania igual são consideradas irrevogáveis; os direitos garantidos pela justiça não estão sujeitos a negociações políticas nem ao cálculo de interesses sociais. 
determinado fato, principalmente quando o tema escoIhido é pouco explorado, dificultando a formulação de hipóteses específicas; com abordagem quantitativa.

Os dados utilizados para analisar a qualidade das oportunidades educacionais e como elas se manifestam nos municípios da RMC foram obtidos nos portais do Instituto Brasileiro de Geografia e Estatística (IBGE), Índice de Oportunidades da Educação Brasileira (IOEB), Instituto de Pesquisa e Economia Aplicada (Ipea), Instituto Nacional de Estudos e Pesquisas em Educação (Inep), Índice de Desenvolvimento Humano (IDH) e Índice Paulista de Vulnerabilidade Social (IPVS).

Os dados obtidos foram quantificados através do uso de ferramentas de Sistemas de Informações Georreferenciadas (SIG). Logo, foi analisada a distribuição de oportunidades educacionais na RMC e suas relações com as variáveis que formam o IOEB. A partir dos dados obtidos, foi possível a elaboração de mapas temáticos de todas as variáveis que compõem o IOEB nos 19 municípios que integram a RMC, sendo eles: Americana, Artur Nogueira, Campinas, Cosmópolis, Engenheiro Coelho, Holambra, Hortolândia, Indaiatuba, Itatiba, Jaguariúna, Monte Mor, Morungaba, Nova Odessa, Paulínia, Pedreira, Santa Barbara D'Oeste, Sumaré, Valinhos e Vinhedo.

A ilustração da distribuição das oportunidades fornece uma melhor visualização sobre as demandas primordiais dos municípios, suas fragilidades e potencialidades. Tais aferições permitem que os municípios possam fazer mudanças de políticas públicas e boas práticas administrativas que possibilitem atingir alto desempenho em determinada variável.

Posteriormente, os mapas temáticos, concomitante com análise de gráficos, foram utilizados para fazer análises comparativas sobre como as variáveis são distribuídas, e quais relações possuem diretamente com os índices de vulnerabilidade social e desenvolvimento humano.

\section{RESULTADOS}

Através da análise e quantificação dos dados consultados nos sites do INEP (Instituto Nacional de

8 Os mapas foram elaborados com auxílio do programa ArcGIS, que é um software utilizado para trabalhar com Sistemas de Informações Georreferenciadas (SIG).
Estudos e Pesquisas Educacionais), IPEA (Instituto de Pesquisa Econômica Aplicada), IOEB, IBGE (Instituto Brasileiro de Geografia e Estatística), IDH (Índice de Desenvolvimento Humano) e IPVS (Índice Paulista de Vulnerabilidade Social), foram obtidos materiais que possibilitaram a compreensão sobre a distribuição das oportunidades educacionais na RMC, quais municípios se destacam nas variáveis do indicador e também as suas fragilidades. No Mapa 1, pode-se visualizar como as oportunidades educacionais estão distribuídas geograficamente na RCM à luz do IOEB.

\section{Mapa 1 - Distribuição das oportunidades educacionais} na Região Metropolitana de Campinas à luz do Índice de Oportunidades da Educação Brasileira.

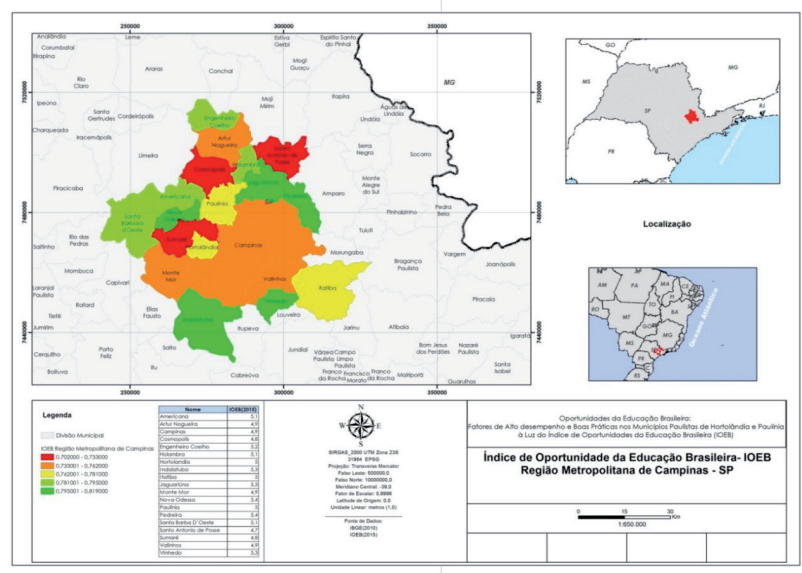

Fonte: Elaboação do autor, a partir de dados obtidos no site do IOEB (www.ioeb.org.br, acesso: 10/09/2018).

O modelo cartográfico 1 evidencia que a distribuição das oportunidades educacionais não está diretamente relacionada aos fatores socioeconômicos, pois, municípios como Pedreira e Nova Odessa estão no topo do ranking do IOEB e, quando analisados em relação aos fatores econômicos e aos fatores de vulnerabilidade social, estão abaixo de municípios como Campinas, Paulínia e Vinhedo. Os resultados dessas análises prévias, criam a hipótese que os altos níveis obtidos desses municípios estão intrínsecos às práticas de gestão que prezam pela eficiência e bom desempenho dos atores envolvidos no processo socioeducativo.

No entanto, os dados de municípios de Pedreira, Nova Odessa e Jaguariúna não são tão surpreendentes como o desempenho de Hortolândia, visto que se trata de um município que apresenta, em seu 
interior, altas taxas de vulnerabilidade social. O Mapa 2 foi confeccionado para permitir uma melhor visualização do IPVS entre dos dados da RCM quando cruzados com o IOEB.

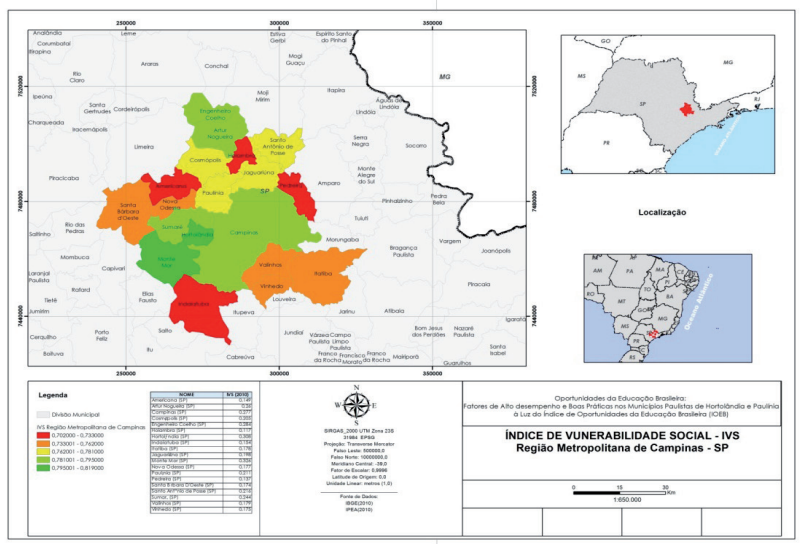

Fonte: Elaboração do autor, a partir de dados obtidos nos sites do IOEB e IPVS (www.ioeb.org.br , acesso em 25/09/2018; www.seade.org.br. Acesso em 25/09/2018)

A literatura aponta que as desigualdades socioeconômicas estão relacionadas ao desempenho dos alunos (SOARES, 2007). Nesse sentido, a busca de eficiência em gestão escolar pode ser um fator que permita equidade social, uma vez que municípios com alta taxa de vulnerabilidade social, no caso de Hortolândia, atingem níveis de educação maiores que municípios que possuem melhores condições sociais. No tocante à importância das práticas escolares para a melhoria da performance em avaliações externas, estudos apontam que "algumas escolas, públicas e privadas, pelas suas políticas e práticas pedagógicas conseguem fazer diferença no desempenho de seus alunos mesmo quando eles são socioeconomicamente desfavorecidos" (SOARES, ANDRADE, 2006, p. 01). Neste sentido, mesmo as unidades escolares estando situadas em regiões de vulnerabilidade social, ações de boas práticas escolares e eficiência em gestão garantem que seus alunos atinjam resultados elevados, podendo, dessa forma, garantir melhores oportunidades educacionais (CALDERÓN et al, 2015).

Quando analisada a relação do IOEB com o Índice de Vulnerabilidade Social (IVS) e Índice de Desenvolvimento Humano (IDH), anos finais, percebe-se o quanto o município de Hortolândia se destaca em re- lação ao município de Paulínia quando cruzados com os dados referentes ao desempenho nas avaliações do Ideb, conforme apresentado no Gráfico 1.

Gráfico 1 - Relação do Ideb com o Índice de Desenvolvimento Humano e Índice de Vulnerabilidade Social.

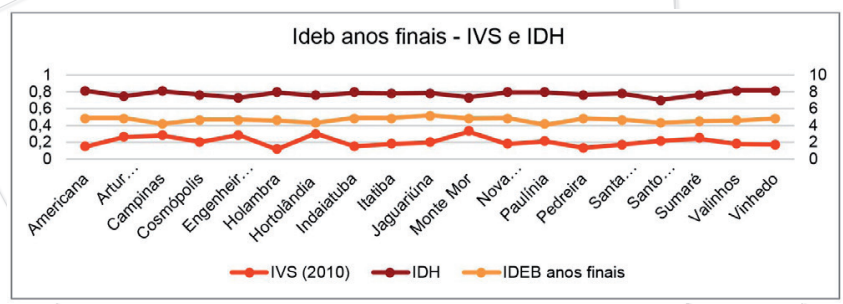

Fonte: Elaboração do autor, a partir de dados obtidos nos sites do IOEB, IBGE, IDH e IPVS.

Uma outra variável que chamou atenção foi a taxa líquida de matrícula apresentada pelo município de Hortolândia, pois como aponta a literatura, áreas vulneráveis têm como tendência apresentar altas taxas de evasão, porém esse conceito não se aplica a Hortolândia, visto que sua taxa de matrícula, na faixa de 15 a 17 anos, está acima da média, como apresentado no Gráfico 2.

Gráfico 2 - Relação entre a taxa líquida de matrícula e o Índice de Vulnerabilidade Social.

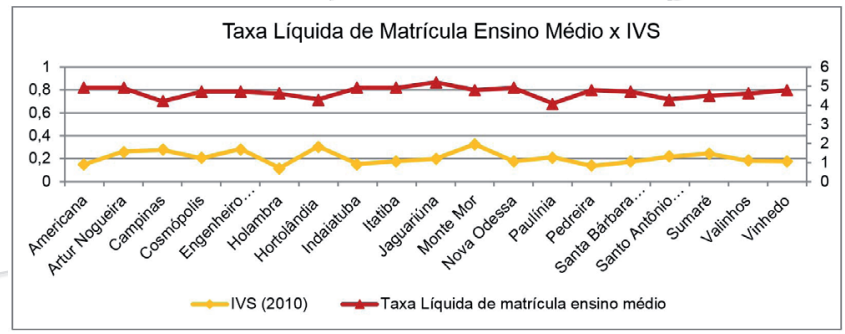

Fonte: Elaboração do autor, a partir de dados obtidos no site do IOEB.

De modo geral, a partir dos dados abordados, com relação à distribuição de oportunidades educacionais em áreas de vulnerabilidade social, os estudos apontam que existe uma relação direta entre as duas avaliações, porém ao analisar os dados à luz do IOEB, identifica-se que cidades mesmo encontrando-se em áreas de vulnerabilidade social conseguem ofertar oportunidades educacionais em níveis mais elevados 
do que municípios diametralmente opostos. Na RMC, o município de Hortolândia, mesmo possuindo as menores taxas de IDH e maiores taxas de acordo com o IPVS, possui oportunidades educacionais acima da média da RMC.

Tal perspectiva prediz dizer que a gestão pública de Hortolândia tem se mostrado eficiente na busca em oferecer melhores oportunidades educacionais acima da média da RMC, mesmo apesar dos problemas sociais presentes no interior do município. Assim, entende-se que a busca pela equidade social está atrelada a políticas públicas eficientes e boas práticas administrativas.

\section{CONSIDERAÇÕES FINAIS}

O presente estudo teve a pretensão de compreender através da análise das variáveis relacionadas a fatores de insumos e resultados que compõem o Índice de Oportunidades da Educação Brasileira (IOEB), as principais tendências em termos de oportunidades educacionais existentes nos municípios que constituem a Região Metropolitana de Campinas.

A utilização do IOEB para explorar as tendên- cias e mapeamento das oportunidades educacionais na RMC, permitiu criar uma simplificação da realidade regional. Pode-se apontar algumas fragilidades apresentadas por alguns municípios e potencialidade de outros, contudo, para uma análise mais precisa sobre as oportunidades educacionais ofertadas seria necessário além de uma análise quantitativa (que foi usada no presente estudo), uma análise qualitativa para que se possa verificar se os dados apresentados refletem a realidade.

Mesmo não sendo um instrumento validado para a implantação de políticas públicas educacionais, o IOEB pode ser utilizado como um passo importante para que municípios e estados possam redirecionar os seus sistemas avaliativos. Além das descrições dos dados qualitativos das variáveis que compõe o indicador, é importante estabelecer as relações dos resultados obtidos em cada município, em cada unidade escolar, e quais foram os processos educativos ali estabelecidos. Neste contexto, cabem aos gestores realizar as interpretações de suas realidades, formular e desenvolver políticas públicas para garantir a melhoria das oportunidades educacionais.

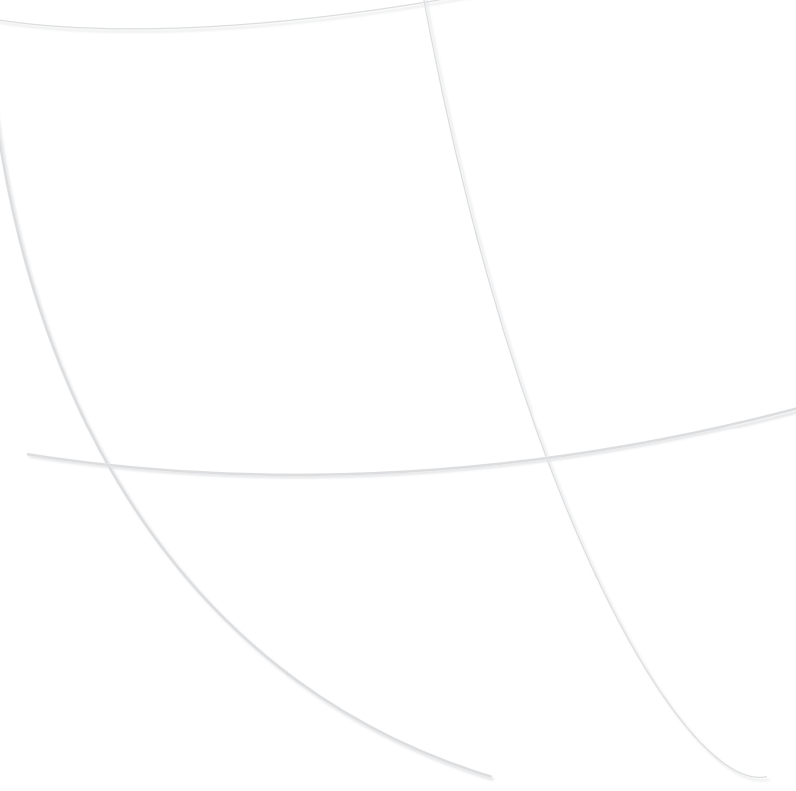




\section{REFERÊNCIAS}

AZEVEDO, S. J. S. de. Segregação e oportunidades de acesso aos serviços básicos de saúde em Campinas: vulnerabilidades sociodemográficas no espaço interurbano. 2009. Tese (Doutorado) - Instituto de Filosofia e Ciências Humanas, Universidade Estadual de Campinas, Campinas, 2009.

BICHIR, R. M. Segregação e acesso a políticas públicas no município de São Paulo. 2006.

Dissertação (Mestrado) - Faculdade de Filosofia, Letras e Ciências Humanas, Universidade de São Paulo, São Paulo, 2006.

BIRDSALL, N.; BRUNS, B.; SABOT, R. H. Education in Brazil: planning a bad hand badly. In: BIRDSALL, N.; SABOT, R. (Eds.). Opportunity forgone: education in Brazil. InterAmerican Development Bank, 1996.

BUGNI, R. P.; JACOB, M. S. Índice de vulnerabilidade social: uma análise da cidade de São Paulo. In: MARGUT B. O. et al. Territórios em números: insumos para políticas públicas a partir da análise do IDHM e do IVS de UDHs e regiões metropolitanas brasileiras. 2. ed. Brasília: Ipea, 2017. p. 336.

CALDERÓN, A. I. et al. O prêmio escola nota 10: meritocracia e cooperação para a melhoria do desempenho escolar 1. Ensaio: avaliação e políticas públicas em educação, 23(87), 517-540.

CENTRO DE LIDERANÇA PÚBLICA. Índice de oportunidades da Educação Brasileira, 2015. Disponível em: <http://bit.ly/1MMjMZk>. Acesso em: 07 abr. 2017.

CUNHA, J. M. P. et al. Expansão metropolitana, mobilidade especial e segregação nos anos 90: o caso da RM de Campinas. In: CUNHA, J. M. P. (Org.). Novas metrópoles paulistas: população, vulnerabilidade e segregação. Campinas, SP: Núcleo de Estudo da População - NEPO/ Unicamp, 2006.

CUNHA, J. M. P. et al. Projeto vulnerabilidade: sumário de dados da Região Metropolitana de

Campinas. Campinas, SP: NEPO/UNICAMP, 2009.
FARAH, M. F. S. Disseminação de inovações e políticas públicas e espaço local. O\&S, v. 15, n. 45 p. 107126, 2008.

FLORES, C. Consequências da segregação residencial: teoria e métodos. In: Cunha, J. M. P. (Ed.). Novas Metrópoles Paulistas: população, vulnerabilidade e segregação. NEPO/UNICAMP, p. 197-230, 2006.

GALSTER, G. C.; KILLEN, S. P. The geography of metropolitan opportunity: a reconnaissance and conceptual framework. Housing Policy Debate, Alexandria, v. 5, n. 1, p. 7- 43, 1995.

GIL, A. C. Como elaborar projetos de pesquisa. 4. ed. São Paulo: Atlas, 2002.

ÍNDICE DE OPORTUNIDADES DA EDUCAÇÃO BRASILEIRA - IOEB. Disponível em: <http://www. ioeb.org.br>. Acesso em: 17 abr. 2017

ÍNDICE PAULISTA DE VULNERABILIDADE SOCIAL - IPVS. Setores Censitários do Município de São Paulo, 2000. Disponível em: <http://www9.prefeitura. sp.gov.br/sempla/mm/mapas/indice6_1.pdf> Acesso em: 17 abr. 2017

INSTITUTO BRASILEIRO DE GEOGRAFIA E ESTATÍSTICA - IBGE. Mapas. Disponível em: <ftp://geoftp. ibge.gov.br/organizacao_do_territorio/malhas_territoriais/malhas_municipais/mun icipio_2015/UFs/SP/>. Acesso em: 17 abr. 2017.

INSTITUTO DE PESQUISA ECONÔMICA APLICADA - IPEA. Atlas da vulnerabilidade social. Disponível em: <http://ivs.ipea.gov.br/index.php/pt/> Acesso em: 17 abr. 2017.

INSTITUTO NACIONAL DE ESTUDOS E PESQUISAS EDUCACIONAIS ANÍSIO TEIXEIRA - INEP. Disponível em: < http://www.inep.gov.br/>. Acesso em: 17 abr. 2017. 
JENCKS, C. S; BROWN, M. D. Effects of High Schools on their Students. Harvard Center for Educational Policy Research, 1972.

KAZTMAN, R.; FILGUEIRA, F. As normas como bem público e privado: reflexões nas fronteiras do enfoque ativos, vulnerabilidades e estrutura de oportunidades (Aveo). In: CUNHA (Org). Novas metrópoles paulistas: população, vulnerabilidades e segregação. Campinas: NEPO, Sitta, 2006.

LENCIONI, Sandra. Região e Geografia. São Paulo: Edusp, 1999.

KAZTMAN, R.; RETAMOSO, A. Segregación espacial, empleo y pobreza en Montevideo. CEPAL, Santiago de Chile, n. 85, p. 131-148, abr. 2005.

KOSLINSKI, M. C.; ALVES, F. Novos olhares para as desigualdades de oportunidades educacionais: a segregação residencial e a relação favela-asfalto no contexto carioca. Educ. Soc., Campinas, v. 33, n. 120, p. 805-831, jul./set. 2012.

MADAUS, G. F.; AIRASIAN, P. W.; KELLAGHAN, T. School effectiveness: a reassessment of the evidence. New York: McGraw-Hill Book Company, 1980.

MADAUS, G.; RUSSELL, M.; HIGGINS, J. The paradoxes of high stakes testing. Charlotte: Information Age Publishing, 2009.

MARCONI, E. M.; LAKATOS, M. de A. Fundamentos de metodologia científica. 5. ed. São Paulo: Atlas, 2003.
RAWLS, J. A theory of justice. Revised Edition, Cambridge: Harvard University Press, 2000, p. 560.

RIBEIRO, L. C. Q.; KOSLINSKI, M. C. A cidade contra a escola? o caso do município do Rio de Janeiro. Revista Contemporânea de Educação, Rio de Janeiro, v. 4, n. 8, p. 351-378, 2009.

RIBEIRO, V. M. Que princípio de justiça para a educação básica? Cad. Pesquisa, v. 44, n. 154, p. 1094-1109, out./dez. 2014.

SANTOS, M. A urbanização brasileira. São Paulo: Hucitec, 1998.

SOARES, J. F.; ANDRADE, R. J. Nível socioeconômico, qualidade e equidade das escolas de Belo Horizonte. Ensaio: avaliação e políticas públicas em educação, Rio de Janeiro, v. 14, n. 50, p. 107-126, 2006.

SOARES, J. F. Melhoria do desempenho cognitivo dos alunos do ensino fundamental. Cadernos de Pesquisa, São Paulo, v. 37, n. 130, p. 135-160, 2007.

SOARES, J. F.; XAVIER, F. P. Pressupostos educacionais e estatísticos do Ideb. Educação \& Sociedade, v. 34, n. 124, p. 903-923, 2013.

TORRES, H. G.; GOMES, S. Desigualdade educacional e segregação social. Novos Estudos Cebrap: dossiê espaço, política e políticas na metrópole paulistana, São Paulo, 2002.

WILSON, W. J. The truly disadvantaged: the inner city, the underclass and public policy. Chicago: University of Chicago, 1987. 